\title{
A educação do corpo feminino no Correio da Manhã (1901-1974): magreza, bom gosto e envelhecimento*
}

\author{
Raquel Discini Campos**
}

\section{Resumo}

Este trabalho se insere nas fronteiras dos estudos de gênero, história social da imprensa e história da educação. Discute o papel desempenhado pelo impresso carioca Correio da Manhã (19011970), um dos mais expressivos periódicos brasileiros em circulação no século XX, na educação das mulheres do período. Enfatiza, em especial, os anos de 1930, destacando os ensinamentos relativos à aquisição do bom gosto feminino, o que, naquele tempo, passou a ser sinônimo de esbeltez e juventude.

Palavras-chave: Correio da Manhã, Corpo Feminino, Gênero, História da Educação.

Recebido para publicação em 18 de janeiro de 2014, aceito em 17 de março de 2015. A pesquisa conta com o apoio do CNPQ e da FAPEMIG. Parte deste texto foi apresentada no XI Congresso Ibero-americano de História da Educação.

** Professora dos Programas de Pós-Graduação em Educação e Comunicação, da Faculdade de Educação da Universidade Federal de Uberlândia, Uberlândia, MG, Brasil.raqueldiscini@uol.com.br 
The Education of The Female Body in The Newspaper Correio da Manhã (1901-1974): Slimness, Good Taste and Aging

\section{Abstract}

The present work is inserted in the boundaries of Gender Studies, Social History of Press and History of Education. It discusses the role played by a newspaper from Rio de Janeiro, Correio da Manhã (1901-1970), one of the most expressive Brazilian periodicals in circulation in the $20^{\text {th }}$ century and that contributed to women's education during that time. It emphasizes, specially, the decade of 1930, highlighting teachings concerning the acquisition of good taste by women, which, back then, became a synonym of slenderness and youth.

Key Words: Correio da Manhã, Newspapers, Female Body, Gender; History of Education. 


\section{O impresso}

O jornal Correio da Manhã, fundado em 1901, no Rio de Janeiro, por Edmundo Bittencourt, foi um dos impressos mais longevos e de maior repercussão social na história recente do país. Seu ocaso se deu definitivamente em 1974, após longa agonia financeira gerada por drástica queda de anunciantes, decorrente de sua oposição à ditadura militar brasileira (1964-1985).

Para os que lá trabalharam, como os jornalistas Luiz Carlos de Souza, Luiz Bravo e Fuad Atala, o Correio foi uma "escola de jornalismo e de vida", "faculdade sem vestibular" "escola incomparável" da arte e da técnica de se fazer um jornal (Atala, 2002:39; Bravo, 2002:69; Souza, 2002:72, respectivamente).

O jornalista e deputado federal Márcio Moreira Alves, em suas memórias, também relembra o caráter marcadamente oposicionista do impresso, e igualmente o identifica com uma espécie de "escola prática" da profissão, adjetivações recorrentes nas lembranças da maioria dos que passaram por aquela redação.

O Correio da Manhã foi, durante 50 anos, num tempo em que não existiam rádio nem $\mathrm{TV}$, o jornal político mais influente do Brasil. Era mais que um jornal. Era uma escola de jornalismo, uma fortaleza política, uma trincheira de combate, quase sempre na oposição (Alves, 2002:48). ${ }^{1}$

Conforme relatado em depoimento para os Cadernos da Comunicação do Rio de Janeiro, publicação elaborada em memória aos primeiros impressos cariocas, do interior daquela "escola" Atala observaria o Correio atingir "tiragens diárias superiores a 200.000 mil exemplares" nos anos de 1950 e 1960, um verdadeiro marco de vendagens num país ainda desigualmente letrado.

1 Márcio Moreira Alves, além de jornalista, foi o deputado federal autor do famoso discurso de crítica à ditadura militar brasileira que deflagrou o AI5. Seu mandato foi cassado logo após o pronunciamento. 
Segundo Carlos Heitor Cony (2002), outro de seus reconhecidos colaboradores, o periódico, além de ser um ambiente de aprendizagem para jovens jornalistas, foi espaço peculiar de visibilidade para os que se aventuravam na carreira, já que não ficava restrito apenas às fronteiras cariocas, sendo também distribuído para outras cidades do país. Jornais de localidades menores reproduziam artigos e reportagens publicadas originalmente no Correio e, vez ou outra, detinham-se em comentários daquilo que tinha sido produzido no Rio reduplicação que é ainda hoje traço característico dos mass media contemporâneos.

Conforme demonstrado por Cony, reconhecia-se, tacitamente, que falar para o Correio era falar para as camadas médias urbanas do Brasil, e trabalhar naquela redação era sinal de distinção entre os próprios pares. Aliás, parte significativa dos que passaram pelo prédio da Avenida Gomes Freire, local de funcionamento do impresso, relembra com satisfação o fato de ter feito carreira no célebre jornal. Não por acaso, Rui Castro legitima as lembranças de Cony e Gurjan, ao afirmar que desde menino sonhava em trabalhar no jornal - o que de fato viria acontecer na idade adulta (Castro, 2010).

Trabalhava em outros jornais e percebia que o pessoal do Correio da Manhã era o mais prestigiado nas salas $e$ comitês de imprensa da época. Muitas vezes, uma autoridade, um político, um artista de renome davam uma entrevista coletiva, mas todos percebiam que o entrevistado estava falando apenas para o Correio (Cony, 2002:42).

Entrei para o Correio em 1961, bem foca, inteiramente deslumbrada por estar começando no maior jornal do país. Jornal que meu pai (e toda a minha família) assinava desde sempre (...) (Gurjan, 2002:55).

A aura de respeitabilidade construída em torno do impresso relacionava-se diretamente ao grupo de intelectuais, jornalistas $e$ letrados de toda ordem que ocuparam suas páginas ao longo do 
século XX. Nas primeiras décadas de circulação, por exemplo, contava com a colaboração e o prestígio de figuras como Rui Barbosa (de quem o fundador da empresa, Edmundo Bittencourt, havia comprado o equipamento para dar início ao negócio), Medeiros de Albuquerque, Carlos de Laet, José Veríssimo, Alberto de Oliveira, Leão Veloso, Afonso Celso, Coelho Neto, Evaristo de Morais, Artur Azevedo, dentre outros.

Ao longo das décadas posteriores, Antônio Callado, Otto Maria Carpeaux, Graciliano Ramos, Álvaro Lins, Franklin de Oliveira, Hermano Alves, Janio de Freitas, José Lino Grünewald e Newton Rodrigues foram editores ou revisores. Dentre seus inúmeros colunistas, constavam Carlos Drummond de Andrade, Moniz Viana, Paschoal Carlos Magno, Van Jafa, José Condé, Brito Broca, Octavio de Faria, Jaime Maurício, Eurico Nogueira França, Jorge Leão Teixeira, Sérgio Augusto, Paulo Francis e Nelson Rodrigues.

De fato, pesquisadores sociais da imprensa são enfáticos ao afirmarem que o impresso foi "um dos mais sólidos e prestigiosos formadores de opinião do País" e que "o texto do Correio chegou a ser conhecido como o mais bem escrito de todos os jornais da época" (Cadernos, 2002:21,43). Em suas páginas foram publicados manifestos (como, por exemplo, o Manifesto Pau-Brasil, de Oswald de Andrade, em 1924); editoriais que canalizaram anseios coletivos e que, justamente por isso, se tornaram verdadeiros agentes históricos (caso dos textos que ora defenderam, ora atacaram o governo varguista nos anos de 1930 e 1940, ampararam Juscelino Kubitschek nos anos de 1950, ou incidiram frontalmente contra a ditadura nos anos de 1960 e 1970); e até mesmo grandes equívocos, como é o caso da famosa carta cuja (falsa) autoria foi atribuída pelo jornal a Arthur Bernardes, publicada em primeira página no ano de $1921 .^{2}$

2 Em junho de 1921, o Correio da Manhã publicou uma carta supostamente escrita pelo candidato à presidência, Arthur Bernardes, criticando duramente os militares brasileiros. A falsidade da carta foi mais tarde comprovada e Bernardes eleito em 1922. No entanto, a grande repercussão da missiva colaborou 
Mas não é esse Correio de grandes proporções políticas ou culturais que se pretende, por ora, observar, mesmo sabendo que até para ele os pesquisadores que se dedicam a vasculhar a história da imprensa têm pouco voltado o olhar. ${ }^{3}$ Pelo contrário, objetiva-se, neste artigo, destacar um de seus aspectos ainda agora pouco iluminados. Quem sabe porque se trate de um traço cotidiano $e$, talvez por isso, pouco rememorado tanto pelos seus artífices quanto pelos pesquisadores que o tomam como fonte; quem sabe porque se trate de um assunto que já foi considerado "menor" no campo historiográfico, se comparado a outros tidos como mais relevantes.

\section{Correio feminino}

Refiro-me aos ensinamentos, dicas, receitas, conselhos, artigos e propagandas destinadas especificamente à leitura feminina, presentes nas páginas do Correio desde 1901 e que ganharam, ao longo dos anos subsequentes, diferentes espaços na diagramação do jornal. Foram distribuídos por décadas, reiteradamente, por todo o corpo do impresso: ora dispersos aqui $e$ ali, ora condensados em cadernos de variedades e suplementos específicos. Além disso, tais ensinamentos apareceram com diferentes abordagens temáticas, tons e roupagens, conforme o contexto social em que foram publicados - mas estiveram ininterruptamente presentes, do início ao fim, na história do jornal.

Num tempo em que as revistas destinadas exclusivamente à leitura das mulheres ainda não tinham assumido completamente o monopólio discursivo sobre o universo feminino - fato que seria incontestável, conforme demonstrou Buitoni (2009), a partir de meados dos anos de 1950, com a segmentação do mercado

decisivamente para a série de rebeliões militares que marcaram os anos de 1920 no Brasil.

3 Diferentemente dos historiadores que escrevem a história do Brasil utilizando a imprensa como fonte. Muitos dos que se debruçam sobre a história social, cultural e política nacional na primeira metade do século XX utilizam matérias e editoriais do Correio. 
gerada pela chegada de Capricho (1952), Cláudia (1961) e afins -, eram os jornais de variedades e de ampla circulação, acrescidos de seus suplementos femininos, como é o caso do Correio, que exerciam a função de falar para e sobre as mulheres.

Bem sabemos que as leitoras de épocas distintas pelas quais circulou o periódico, como 1910 e 1970, por exemplo, guardavam diferenças sociais e culturais significativas entre si. Se pensarmos no Correio como um produto duradouro voltado para um determinado nicho de mercado e se levarmos em conta características particulares do grupo social ao qual ele se dirigia, tais como grau de letramento, geração, etnia e classe social, observaremos que muitas das leitoras de 1910 (prioritariamente urbanas, de classe média ou alta, brancas e adultas) davam os primeiros passos em torno da construção da própria cidadania, independentemente de pais e maridos, defendendo (ou não) o direito ao voto e ao divórcio, num processo que os pesquisadores do tema identificaram como uma "primeira onda feminista" movimento que ocorreu não só no Brasil, mas em boa parte do mundo Ocidental (Soihet, 1974; Rago, 1997; Pinto, 2003).

Já as leitoras de 1970, por sua vez, usufruíam, pelo menos idealmente, desses direitos conquistados pelas gerações anteriores, e passavam a pleitear e a discutir outros temas não só públicos, mas também privados, como é o caso da autoridade sobre o próprio corpo, sobretudo no que concernia ao prazer sexual e ao controle da natalidade. Trata-se da "segunda onda feminista", à qual se refere a historiografia contemporânea (Perrot, 2007; Pedro, 2012).

No entanto, independentemente se mais desejosas de referências francesas fin de siècle, associadas ao bem viver, ao luxo e a elegância parisienses, e ainda bastante restritas ao império do lar; ou se realmente mais independentes de antigos papéis sociais e igualmente próximas dos ideais contemporâneos relacionados à agilidade, à independência e à desenvoltura femininas; $e$ a despeito de se inspirarem mais na teatralidade belle époque de Sarah Bernardt, ou no mito cinematográfico hollywoodiano de Marylin Monroe, sem dúvida, a preocupação 
com a conquista e a manutenção da beleza foi ensinamento diário dado por homens e mulheres às leitoras do impresso.

Bem sabemos que não só as consumidoras do Correio eram alvo habitual de tal aprendizagem. Pesquisadores vêm demonstrando que o assunto é tema inescapável quando se debruçam sobre as publicações dirigidas à mulher desde meados do século XIX (Buitoni, 2009, Luca, 2012, Sant'anna, 2012). No caso particular do Correio, tal posicionamento respondia a uma demanda própria das leitoras, inseridas num universo social em que a beleza passou a ser abarcada não mais apenas como uma espécie de dom divino, conforme representado pela humanidade desde tempos imemoriais, ou mesmo como um presente da natureza, segundo aventado nas cartas $e$ tratados de embelezamento da Idade Moderna em diante. Nos séculos XIX, XX e XXI, a beleza passou a ser compreendida e ensinada como uma das mais importantes conquistas pessoais imagináveis para as mulheres. Mais do que uma conquista, uma verdadeira obrigação feminina, uma questão de bom gosto e boa educação (Perrot, 1992; 2007; Vigarello, 2006; Sant'anna, 2005; 2012).

Nesse aspecto, vale retomar o ensinamento original de Pierre Bourdieu, que demonstrou ao longo de sua obra que o dito bom gosto é resultante de um processo gerado tanto na família quanto na escola, bem como nas mídias contemporâneas, dentre outros veículos $e$ instituições educativas, e não o resultado inato de uma sensibilidade dada a priori. A associação entre beleza, bom gosto e boa educação são faces de um mesmo fenômeno de hierarquização de determinados grupos sociais em relação a outros (Bourdieu, 2008). No caso do Correio, de um lado, temos as leitoras de classe média ou alta: belas, elegantes e de bom gosto; de outro lado, todas as outras.

\section{Ser bela no Correio dos anos de 1930}

Os anos de 1930, em especial, foram pródigos no que concerne à discussão sobre o tema do embelezamento relacionado ao bom gosto e à boa educação, bem como à distinção entre 
belas e feias. Tempos de coroamento de antigos princípios médico-higienistas que relacionavam diretamente beleza, saúde, exercícios físicos, alimentação, raça e identidade nacional, conforme demonstram os casos não só dos sempre lembrados totalitarismos europeus, mas também os exemplos americanos, como é o caso do Brasil, da Argentina e dos Estados Unidos, dentre outros.

Não por acaso, no Brasil, um certo Dr. Pires se tornou um reconhecido conselheiro das mulheres da época, prescrevendo receitas que relacionavam diretamente saúde e beleza em diversos periódicos (Sant'anna, 2012). Interessante observar o tom racional e técnico empregado pelo médico para se dirigir às leitoras, condizente com a voz "scienthifica" da medicina, campo em franco processo de sacralização no período. Ressalta-se o ensino de metodologias destinadas à aplicação cotidiana, a prescrição de receitas de fácil execução e resultados supostamente eficientes para o embelezamento diário.

Ao que parece, os artigos de Pires eram de grande interesse para as leitoras, já que vez ou outra o impresso abria espaço para a publicação das cartas enviadas por elas como resposta ao que liam, corroborando a assertiva de que todo texto prevê um determinado tipo de leitor, conforme demonstraram pioneiramente Darton (1995) e Chartier (1996). Para este último, aliás, "cada leitor, a partir de suas próprias referências individuais ou sociais, históricas ou existenciais, dá um sentido mais ou menos singular, mais ou menos partilhado, aos textos de que se apropria" (Chartier, 1996:20).

Assim, observamos nos excertos abaixo: confiança entre quem lê e quem escreve, prescrições racionais para a perda eficiente de peso, referências a centros de beleza internacionais atestando um pretenso cosmopolitismo compartilhado entre escritores e leitores.

Há um mez, approximadamente, escrevemos um artigo sobre o moderno tratamento da obesidade pelos sáes de parafina. Tivemos a opportunidade, então, de relatar as 
vantagens do emprego desses sáes, principalmente pelo facto de ser um methodo inteiramente inoffensivo à saúde $e$ de uma facillidade extrema. Conforme esperavamos, varias dezenas de cartas nos foram dirigidas solicitando maiores detalhes sobre esse novo $e$ interessante methodo tão usado hoje em dia em Paris e Nova York. Na medida do possível iremos responder às leitoras (...)

(Um novo tractamento para emagrecer pelo Dr. Pires - com pratica nos hospitaes de Paris, Berlim e Vienna. Correio da Manhã, 13/09/1936).

De uma leitora recebemos a seguinte carta, com interessante e propicio methodo para emagrecer:

Sr. Redactor do Correio da Manhã:

Tendo lido no vosso supplemento de 7 do corrente um artigo sobre a obesidade $e$ vendo o interesse que tendes pela saúde de vossos leitores, eu vos vou enviar um regimen que talvez vos possa interessar, pois julgo-o infalivel se for bem applicado. Eu o experimentei e assim varias pessoas de minhas relações. Foi com elle que perdi 11 kilos em um mez e meio, e uma pessoa pesando 102 kilos emmagreceu em pouco tempo 22 kilos, sem alteração alguma maléfica para a saúde, pois além de não ser fatigante, póde ser bastante variado. Queira receber as minhas saudações.

Uma leitora do jornal.

PS, junto vos envio a receita em francez, visto me ser bastante difícil fazel-o em portuguez.

(Regimen para emmagrecer. Correio da Manhã, 14/08/1937).

Mas não eram apenas médicos como Pires que ensinavam às leitoras do Correio como manter a boa forma $e$ a juventude incólumes, pelo contrário. Reatualizando antigos truques, dicas e confidências de beleza, a "conselheira" Eva "conversava" com "amigas" leitoras dos anos de 1930, ávidas por dicas que retardassem os efeitos do envelhecimento, e que ao mesmo tempo combatessem os males físicos já instaurados porque trazidos pela inexorável passagem do tempo. 
Os aconselhamentos giravam em torno de ensinamentos práticos misturados às propagandas, não muito dissimuladas, de produtos específicos voltados para o embelezamento do corpo $e$ do rosto. O tom é muito diferente daquele utilizado pelo Dr. Pires. Nesse caso, a estratégia persuasiva é a da afetividade. Trata-se de uma espécie de convencimento decorrente da intimidade possivel apenas entre iguais. Lipovetsky (2007:160) identificou claramente tal fenômeno em terras europeias, ao indicar que "martelando a ideia de que a beleza pode ser comprada, o mundo do reclame educou as mulheres para uma visão consumista de beleza”.

Tem razão, minha querida Lucia: a belleza das formas é o reflexo da harmonia que deve existir na alma. O corpo da mulher é uma flor delicada que precisa sempre de mil cuidados. E Mm. Jacqueline é a jardineira ideal que conhece todos os segredos que tornam mais bonitas as mulheres, flores vivas.

Vá pois sem demora, querida Lucia, ao mágico Salão Azul da Praia do Flamengo 380 e voltará de lá encantada (...) Não deixe de adquirir a "Vigueur de Seins", ultima descoberta scientifica de Paris: desenvolve o busto atrophiado; torna os seios bonitos e rijos e renovando os tecidos realiza o ideal de conservar a mocidade. $\mathrm{O}$ tratamento que póde ser feito em casa, é rápido, simples e absolutamente garantido.

Se você quizer, poderemos ir juntas, uma tarde destas, ao Salão Azul e nunca mais você deixará de freqüentar aquelle templo da vaidade que torna tão bonitas as mulheres!

Um longo abraço de

EVA. (A belleza das formas. Correio da Manhã, 28/05/1933).

Astarte, assim como Eva, também era hábil em misturar conselhos práticos e publicidade, transformando seus "mandamentos" ou "decálogos" numa espécie de rotina aparentemente muito agradável, mas, não por isso, menos disciplinada e exigente para aquelas que a praticavam com os pés no Brasil - e a cabeça em Paris e Nova York. As expressões, nomes e pseudônimos grafados em francês, assim como o 
conjecturado cosmopolitismo dos "conselheiros", são argumentos de autoridade utilizados pelos anúncios da época - mas não apenas por eles, como observado no caso do Dr. Pires.

Os guias da beleza feminina brasileira se esforçavam em demonstrar que viajaram para as capitais mundiais do dito bom gosto, de onde traziam as "últimas novidades" para as leitoras do Correio.

Os dez mandamentos de uma mulher bonita...

$\left.1^{\circ}\right)$ Cultivards a tua belleza sobre todas as coisas, por isso serds alegre de gênio, perseverante nos tratamentos e farás exercício para conservar a tua agilidade.

$2^{\circ}$ ) Cuidards de tua pelle com a máxima constancia: limpards o teu rosto de manhã e à noite com o HUILE ROMAINE ANTIQUE, passando em seguida a LOÇÃO $e$ CREME RADIA. A tua cútis assim terá a frescura e o viço da camélia.

$\left.3^{\circ}\right)$ Terds cuidado Maximo, também, em applicar duas vezes na semana a famosa MASCARA DE JUVENTUDE, conseguirás assim que tuas feições readquiram o mesmo aspecto de tua mocidade em flor.

$\left.4^{\circ}\right)$ Não terds uma ruga siquer, porque usarás os famosos bálsamos, os ANTIRUGAS ESPECIAIS n. 2 ou 8, segundo a tua edade, e terds também cílios maravilhosos e um olhar fascinador, pois fards uso constante da única SEVE CILIAL. (...).

ASTARTE. (Os dez mandamentos da mulher bonita. Correio da Manhã, 19/01/1936).

Ser bela, desde que jovem e magra. $\mathrm{O}$ tópico atravessou o século XX nas páginas do Correio da Manhã, retomando, na verdade, uma questão historicamente relacionada ao universo feminino, presente, conforme demonstrou pioneiramente Perrot (1992; 2007) em relação ao caso europeu, e Sant'Anna (2005; 2012) e Schpun (1999) em relação ao contexto nacional, em inúmeros suportes: tratados médicos e filosóficos, teses e literatura, pinturas e esculturas, currículos escolares destinados às classes femininas e tantos outros. 
No caso específico analisado, tanto num passado mais distante com um mais recente, observamos emergir das páginas daquele impresso uma espécie de pedagogia da beleza que, desde aqueles tempos e além, ensinou às mulheres que sua essência quando devidamente cuidada - era a de ser bonita.

Conforme apontam as pesquisas dedicadas ao tema, as normas do antipeso $e$ antienvelhecimento, que ainda hoje são a tônica dos discursos midiáticos voltados para as mulheres, dominaram desde o fim do século XIX a cultura de massa. A indústria cultural impulsionou sobremaneira a disseminação de tais discursos, ajudando a fazer crer que a própria natureza não só poderia, como deveria, ser melhorada ou até radicalmente transformada com o auxílio de cosméticos, roupas, regimes, exercícios e, mais recentemente, de intervenções cirúrgicas de toda a ordem.

Foi essa indústria que possibilitou a irradiação $e$ a democratização de acesso de todas à categoria de belas. Ao menos aparentemente, qualquer uma poderia alcançar o ideal representado inicialmente em jornais, e posteriormente em revistas, televisão, cinema, concursos e passarelas - desde que dispusesse de tempo e dinheiro para tanto, mas, especialmente, desde que mantivesse inabaláveis certas características morais imprescindíveis para a realização do intento: a constância, a força de vontade e a disciplina.

Eis um exemplo clássico de adestramento do corpo, movimento tão característico dos sujeitos ocidentais desde a aurora dos tempos modernos, ressignificado nos anos de 1930:

Conservar uma silhueta esbelta e elegante é principalmente uma questão de força de vontade e longa perseverança. Um tratamento abandonado em meio caminho nunca poderá produzir um resultado satisfatório; para tal, é necessário seguill-o à risca, pacientemente até o fim (...) Admitte-se, em geral, que uma pessoa adulta, deva pesar normalmente tantos killos quantos centimetros excedem a um metro de altura: 50 kilos, por exemplo, para $1 \mathrm{~m}$. 50 de altura, 60 para $1 \mathrm{~m}$. 60, etc. Esta calculo, approximadamente 
exacto para o homem entre 40 e 50 annos não o é para a mulher. A média para essas, segundo os especialistas é a seguinte:

\begin{tabular}{|l|l|l|l|}
\hline & Idade & Idade & Idade \\
\hline Altura & 20 annos & 30 annos & 40 annos \\
\hline $1 \mathrm{~m} .50$ & 50 kilos & 53 kilos & 56 kilos \\
\hline $1 \mathrm{~m} .60$ & 55 kilos & 57 kilos & 61 kilos \\
\hline $1 \mathrm{~m} .70$ & 62 kilos & 65 kilos & 68 kilos \\
\hline
\end{tabular}

(Em defesa da beleza. Correio da Manhã, 14/08/1937).

Interessante notar que a constituição do "belo sexo", desde o século XIX, relaciona a figura feminina a uma espécie de adorno do mundo social e à ideia de que a mulher é um objeto a ser contemplado pelo olhar do outro. No entanto, é importante destacar que tal movimento igualmente abriu possibilidades para a encenação de um outro tipo de espetáculo. Este último muito mais privado do que público, pois ligado ao prazer da autoadmiração, ou seja, àquilo que Lipovetsky (2007:119) chamou de "espetáculo contemplado narcisicamente", do qual todos somos herdeiros.

A proliferação de quartos, banheiros e espelhos individuais, por exemplo, signos contemporâneos de intimidade burguesa, colaboraram decisivamente para as práticas de autoexame e das ações de embelezamento sobre si. As imagens abaixo, retiradas das páginas do Correio nos anos de 1930, nos dizem muito sobre esse misto de prazer e escravidão, intimidade e disciplina, narcisismo e normalização que acompanhavam os enunciados sobre a beleza da época. Tanto a balança doméstica quanto os exercícios, detalhadamente ilustrados para serem praticados intimamente no recanto do lar, revelam uma prática cotidiana da qual as mulheres foram ao mesmo tempo artífices e objetos.

No anseio constante pelo controle e pela remodelagem das próprias formas, as mulheres acabaram lutando desenfreadamente contra si mesmas, mas também demonstraram a força de antiquíssimas utopias relacionadas ao autocontrole tanto sobre o corpo quanto sobre a mente, revelando, ao fim e ao cabo, a busca pela liberdade individual moderna. 


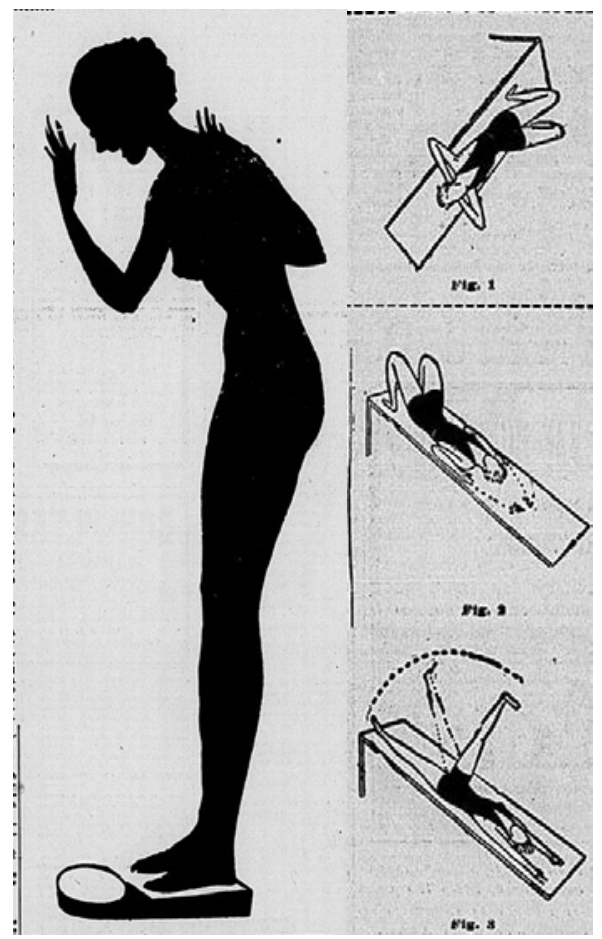

Figura 1

Figura 2:

Correio da Manhã, 1935 Correio da Manhã, 1935

Tão importante quanto provocar deleite sobre si autocontemplando um corpo magro e jovem construído disciplinarmente, era propiciar encantamento ao outro. Assim instruía o Correio: a beleza era a mais importante arma de combate das mulheres, tanto na esfera pública quanto privada. Da mesma forma, no excerto abaixo, podemos observar um certo deslocamento ocorrido em relação às prioridades dadas no trabalho de embelezamento diário.

A ênfase dos preceitos não incide mais apenas sobre o rosto, mas principalmente sobre o corpo, cada vez mais visto, medido, 
exposto, treinado. ${ }^{4}$ Destacam-se, igualmente, nos ensinamentos de Madame Jacqueline, os ecos de uma das mais antigas antinomias ligadas à figura feminina, qual seja: a oposição entre a continência de Maria e a luxúria de Eva. Santidade e pecado amalgamados e ressignificados nos ensinamentos semanais daquela moralista.

A mulher, verdadeiramente mulher, possue mil $e$ um segredos de belleza e de elegância, que são as suas armas de combate e os seus louros de victoria. Não basta ter um bonito rosto; é preciso possuir também uma linha perfeita, um corpo elegante e gracioso.

E o busto, um busto perfeito constitue um dos principais attrativos da mulher. Possuir um lindo collo dispensa, quase, de possuir um lindo rosto. Vós bem o sabeis, ó Filhas de Eva, e ao busto, consagreis mil attenções $e$ cuidados mil...

É preciso que não sejam nem demasiado grandes, nem pequenos demais, esses doces fructos de carne que tantas rimas lindas teem inspirado aos poetas de todos os tempos. Mas ás vezes, a Natureza, ingrata e caprichosa como uma mulher, nega bonitos seios; outras vezes o tempo, a doença, a maternidade fazem com que feneçam essas flores vivas; mas...para quase todos os males, há remédio $e$ as mulheres possuem boas Fadas Amigas que operam verdadeiros milagres. Os seios da mulher são sagrados porque são fontes de vida. E assim como todas as coisas sagradas, devem ser bellos!

Madame JACQUELINE (Correio da Manhã, 24/02/1935).

Os preceitos destinados à prevenção da gordura proliferam e não é à toa que Madame Jacqueline se refere à necessidade de se manter a "linha perfeita". Na verdade, há uma associação direta entre a manutenção ou conquista da beleza e o combate à

4 A esse respeito Vigarello (2009:197) demonstra que o treinamento "vai se impor com o século XX, com uma organização sempre mais exigente: seu desenvolvimento metódico a ponto de se tornar a palavra-chave das pedagogias e das formações físicas". 
gordura. Esta última, um inimigo silencioso, porém sempre presente, que poderia trair a mulher a qualquer momento, se ela não se mantivesse permanentemente vigilante. Prevenir é mais importante do que combater. Eis uma das verdades construídas por variados campos de saber, destacadamente pelos higienistas, ao longo do século XIX, e que repercute com força redobrada ainda em nossos dias.

Um certo "embonpoint" que arredonde as fórmas é, sem dúvida, gracioso: no fim de algum tempo, porém, torna-se uma ameaça para a linha do corpo e, se não for combatido em tempo se transformará em obesidade. Dahi resultará, o envelhecimento, não somente sensível em toda a "allure" como também no estado geral, pois não tardarão a apparecer as palpitações, cansaço, exaggerado, difficuldade de movimentos etc.

É muito mais fácil conter-se a invasão da gordura do que emagrecer (...)

Ouçamos a opinião do emérito hygienista dr.Guignon": seleccionar e dosar os alimentos segundo as calorias que contêm, "eis o segredo do regimen de reducção".

"Duas coisas são essenciaes: a suppressão do pão e de outra bebida que não seja água. Uma chicara de café, sem leite, com muito pouco assucar ou uma limonada levemente adoçada serão permittidas duas vezes ao dia. Desde que o peso desça ao normal cabe á mulher ciosa de seus encantos e attractivos mantel-o inalterável.

Os exercícios physicos, adequados à edade e às condições individuaes, serão um precioso auxiliar para a conservação do equilíbrio das funções vitaes da belleza das formas e a linha esguia que caracteriza a silhueta moderna (KAY. Em defesa da Bellleza. Correio da Manhã, 23/06/1935).

\section{Imprensa feminina e história da educação}

Os preceitos sobre a beleza depreendidos das páginas do Correio não foram apenas alienação. Retratam também a busca das mulheres daqueles tempos por liberdade individual $e$ promoção social. Os ensinamentos destinados à encenação, 
pública ou privada, do espetáculo da beleza, da mesma maneira que enclausuraram a mulheres a certos modelos ideais, também lhes conferiram uma espécie de poder especificamente feminino, historicamente aclamado, exaltado, comentado: o poder de ser bela. Portanto, da norma se extrai, também, uma força e prestígio singulares.

Historiadores e sociólogos demonstraram que a imprensa é parte essencial da produção, consumo, promoção e comunicação de um determinado tipo de beleza feminina. Por seu intermédio, as representações sobre o belo deixaram de ser raras, restritas, por exemplo, às obras de arte ou tratados de anatomia e estética, para se tornaram absolutamente cotidianas e supostamente exequíveis por todas.

A explosão técnica verificada nos séculos $\mathrm{XIX} / \mathrm{XX}$, que barateou custos de produção e dinamizou a distribuição de impressos, permitiu uma inédita irradiação de arquétipos, resultando numa aprendizagem social original. Por isso, podemos tomar a imprensa como vetor principal de técnicas, aconselhamentos, propagandas, concursos, imagens e mais um sem número de ensinamentos relacionados à beleza. Podemos tomá-la, por fim, como fonte para a escrita da história da educação das mulheres contemporâneas. Uma educação não escolar, sem dúvida, mas não por isso menos importante.

A esse respeito, Lipovetsky (2007), em especial, demonstrou que a imprensa criou uma retórica própria, conjugando beleza $e$ consumo. Tal retórica buscou reiteradamente educar as leitoras rumo a um determinado fim: o essencialismo da beleza feminina no mundo social. Para isso, falou sobre o assunto de maneira própria, empregando ora um tom eufórico, ora humorístico. Utilizou-se, ainda, de uma linguagem direta e dinâmica, na qual texto e imagem, conteúdo e forma reforçaram historicamente a definição do feminino como sexo destinado ao belo.

Observar atentamente essa pedagogia da beleza presente no Correio da Manhã no que concerne à educação de corpos e sensibilidades femininas (e também masculinas) do século XX é 
também fazer ver as nossas próprias sensibilidades. Talvez seja uma forma de falar sobre nós mesmos.

\section{Referências bibliográficas}

Alves, Márcio Moreira. O mais influente do Brasil. In: RIO DE JANEIRO (cidade). Secretaria Especial da Comunicação Social. Correio da Manhã: compromisso com a verdade. Rio de Janeiro, Prefeitura Municipal do Rio de Janeiro/Secretaria Especial da Comunicação Social, 2002, pp.48-50. Cadernos da Comunicação. Série Memória. [http://www0.rio.ri.gov.br/arquivo/pdf/cadernos comunicacao/memori a/memoria1.pdf - acesso em: 15 nov. 2013].

ATALA, Fuad. Evocação sem nostalgia. In: RIO DE JANEIRO (cidade). Secretaria Especial da Comunicação Social. Correio da Manhã: compromisso com a verdade. Rio de Janeiro, Prefeitura Municipal do Rio de Janeiro/Secretaria Especial da Comunicação Social, 2002, pp.39-41. Cadernos da Comunicação. Série Memória [http://www0.rio.rj.gov.br/arquivo/pdf/cadernos_comunicacao/memori a/memoria1.pdf - acesso em: 15 nov. 2013].

BouRdieU, Pierre. A distinção: crítica social do julgamento. São Paulo, Edusp/Porto Alegre, Zouk, 2008.

BRAVO, Luiz. Faculdade sem vestibular. In: RIO DE JANEIRO (cidade). Secretaria Especial da Comunicação Social. Correio da Manhã: compromisso com a verdade. Rio de Janeiro, Prefeitura Municipal do Rio de Janeiro/Secretaria Especial da Comunicação Social, 2002, pp.69-71. Cadernos da Comunicação. Série Memória [http://www0.rio.rj.gov.br/arquivo/pdf/cadernos_comunicacao/memori a/memoria1.pdf - acesso em: 15 nov. 2013].

BuITONI, Dulcília. Mulher de papel: a representação da mulher pela imprensa feminina brasileira. São Paulo, Summus, 2009.

CASTRO, Ruy. Para o Correio da Manhã, com uma lágrima. Observatório da Imprensa

[http://www.observatoriodaimprensa.com.br/circo/cir130620013.htm - acesso em 7 jul. 2010].

CHARTIER, Roger (org.). Práticas de Leitura. São Paulo, Estação Liberdade, 1996. 
CONY, Carlos Heitor. Da necessidade de falar bem. In: RIO DE JANEIRO (cidade). Secretaria Especial da Comunicação Social. Correio da Manhã: compromisso com a verdade. Rio de Janeiro, Prefeitura Municipal do Rio de Janeiro/Secretaria Especial da Comunicação Social, 2002, pp.42-44. Cadernos da Comunicação. Série Memória [http://www0.rio.ri.gov.br/arquivo/pdf/cadernos comunicacao/memori a/memoria1.pdf - acesso em: 03 dez. 2013].

GURJAN, Fernanda. Vamos falar de mulheres? In: RIO DE JANEIRO (cidade). Secretaria Especial da Comunicação Social. Correio da Manhã: compromisso com a verdade. Rio de Janeiro, Prefeitura Municipal do Rio de Janeiro/Secretaria Especial da Comunicação Social, 2002, pp.55-57. Cadernos da Comunicação. Série Memória [http://www0.rio.ri.gov.br/arquivo/pdf/cadernos_comunicacao/memori a/memoria1.pdf - acesso em: 15 nov. 2013].

LiPOVETSKY, Gilles. A terceira mulher. São Paulo, Cia das Letras, 2007.

LUCA, Tânia Regina. Mulher em revista. In: PEDRO; PINSKY (org). Nova História das mulheres. São Paulo, Contexto, 2012, pp.447-469.

NEIVA, Renata Maria de Oliveira; CAMPOS, Raquel Discini de. A Feira de Utilidades de Clarice Lispector/Helen Palmer e a educação das mulheres no Correio da Manhã (1959/1961). Cadernos de História da Educação, Uberlândia, vol. 13, nº 2, 2014, pp.725-747.

O ESPELHO de Amélia: a feira de Helen Palmer no Correio da Manhã. Direção de Renata Neiva. Coordenação de Raquel Discini de Campos. Intérprete: Maria de Maria. Roteiro: Renata Neiva. Uberlândia, 2014. (27 min.), DVD, color. Documentário acadêmico, sem fins lucrativos. Programa de Pós-Graduação em Tecnologias, Comunicação e Educação da Faculdade de Educação da Universidade Federal de Uberlândia.

PEDRO, Joana Maria. O feminismo de segunda onda: corpo, prazer e trabalho. In: PEDRO; PINSKY (org). Nova História das mulheres. São Paulo, Contexto, 2012, pp.238-259.

Perrot, Michelle (org). Os atores. História da Vida Privada, vol. 4. São Paulo, Cia das Letras, 1992. . Minha história das mulheres. São Paulo, Contexto, 2007. 
PINTO, Céli Regina Jardim. Uma história do feminismo no Brasil. São Paulo, Perseu Abramo, 2003.

RAGO, Margareth. Do cabaré ao lar: a utopia da cidade disciplinar. Brasil 1890-1930. Rio de Janeiro, Paz e Terra, 1997.

SANT'ANNA, Denise Bernuzzi. Cuidados de si e embelezamento feminino: fragmentos para uma história do corpo no Brasil. In: SANT'ANNA (org). Políticas do corpo. São Paulo, Estação Liberdade, 2005, pp.121-140.

Sempre bela. In: PEDRO; PINSKY (org). Nova História das mulheres. São Paulo, Contexto, 2012, pp.105-125.

SchPun, Mônica Raisa. Beleza em jogo: cultura física e comportamento em São Paulo nos anos 20. São Paulo, Boitempo, 1997.

SOIHET, Rachel. Bertha Lutz e a ascensão social da mulher. Dissertação de Mestrado - História, Universidade Federal Fluminense, Niterói, 1974.

SOUZA, Luiz Carlos. Escola de jornalismo e de vida. In: RIO DE JANEIRO (cidade). Secretaria Especial da Comunicação Social. Correio da Manhã: compromisso com a verdade. Rio de Janeiro, Prefeitura Municipal do Rio de Janeiro/Secretaria Especial da Comunicação Social, 2002, pp.72-74. Cadernos da Comunicação. Série Memória [http://www0.rio.ri.gov.br/arquivo/pdf/cadernos_comunicacao/memori a/memoria1.pdf - acesso em 15 nov. 2013].

TEODORO, Laura Máximo; NeIVA, Renata de Oliveira. Envelhecimento no Correio da Manhã: de 1920 a 1960. Anagrama: Revista Científica Interdisciplinar da Graduação, Brasil, vol. 9, no 2, 2015, pp.1-16 [http://www.revistas.univerciencia.org/index.php/anagrama/article/vie w/8872 - acesso em: 24 set. 2015.

Vigarello, Georges. História da beleza: o corpo e a arte de se embelezar, do Renascimento aos dias de hoje. Rio de Janeiro, Ediouro, 2006.

. Treinar. In: Courtine; Vigarello (org). História do corpo: as mutações do olhar: o século XX. Rio de Janeiro, Vozes, 2009, pp.197-250. 
478 A educação do corpo feminino no Correio da Manhã

\section{Fontes}

ASTARTE. Os dez mandamentos da mulher bonita. Correio da Manhã, Rio de Janeiro, Correio Feminino, p.3, 19 jan. 1936.

EM defesa da beleza. Correio da Manhã, Rio de Janeiro, Correio Feminino, p.6, 14 ago. 1937.

EvA. A belleza das formas. Correio da Manhã, Rio de Janeiro, Supplemento Feminino, p.4, 28 maio 1933.

MadAME Jacqueline. Correio da Manhã, Rio de Janeiro, Correio Feminino, p.4, 24 fev. 1935.

REGIMEN para emmagrecer. Correio da Manhã, Rio de Janeiro, Correio Feminino, p.3, 14 ago. 1937.

KAY. Em defesa da Bellleza. Correio da Manhã, Rio de Janeiro, Correio Feminino, p.3, 23 jun 1935.

UM novo tractamento para emagrecer pelo Dr. Pires - com pratica nos hospitaes de Paris, Berlim e Vienna. Correio da Manhã, Supplemento Feminino, p.4, Rio de Janeiro, 13 set. 1936. 